\title{
Expression of Calcium/Calmodulin-Dependent Protein Kinase in Relation to Dopamine Islands and Synaptic Maturation in the Cat Striatum
}

\author{
H. Newman-Gage and A. M. Graybiel \\ Department of Brain and Cognitive Sciences, Massachusetts Institute of Technology, Cambridge, Massachusetts 02139
}

During pre- and postnatal development the dopamine-containing nigrostriatal afferents of the striatum are arranged as a conspicuous series of patches (the "dopamine islands"). The development of this dopamine island system, which metamorphoses in early postnatal life to the striosomal architecture of the adult, has recently received considerable attention, but the factors initiating and influencing maturation of this architecture are largely unknown. In an attempt to clarify the relationships between the onset of clustering of dopamine-containing afferents, the grouping of neurons within future striosomes and the maturation of synapses in the striatum, we compared the initial prenatal appearance and subsequent development of immunohistochemical markers for the dopamine-containing innervation [tyrosine hydroxylase (TH)-like immunoreactivity], for synaptic vesicles (SV48-like immunoreactivity), and for a phosphorylation-related enzyme $\mathrm{Ca}^{2+} / \mathrm{calmodulin}^{2}$ dependent protein kinase type II (CaM kinase II-like immunoreactivity) that is expressed in virtually all striatal neurons by adulthood.

Here we present evidence that during striatal ontogeny, both neurons and neuropil expressing CaM kinase II-like immunoreactivity and SV48-positive terminals form discrete patches that are in register with dopamine islands. It is CaM kinase II-positive elements, however, rather than the THpositive island fibers (or SV48-positive synapses), that initially form overt clusters. Dopamine-containing fibers begin to innervate the striatal anlage just prior to embryonic day (E) 32. Their distribution follows the general lateral to medial developmental gradient characteristic of the striatum but is not yet distinctly islandic. At this time, CaM kinase II-like immunoreactivity was very weak or not present at all and SV48-like immunoreactivity was undetectable. By E36, CaM kinase II-positive neurons are visible in discrete patches of immunopositive neuropil, but only faint inhomogeneities are detectable in the distribution of TH-positive fibers and scarcely any SV48-like immunoreactivity can be seen. By E45, all 3 markers are focused in typical islandic patterns, and they remain so into the early postnatal period.

\footnotetext{
Received Sept. 28, 1987; revised Jan. 14, 1988; accepted Jan. 15, 1988.

We wish to acknowledge H. F. Hall for contribution of his photographic expertise and to thank Dr. M. B. Kennedy and Dr. W. D. Matthew for generous donation of antisera. This work was supported by NSF BNS8319547, NIH NS07711, the Seaver Institute, and the McKnight Foundation.

Correspondence should be addressed to Dr. H. Newman-Gage, Department of Brain and Cognitive Sciences, E25-618, Massachusetts Institute of Technology, Cambridge, MA 02139.

Copyright (C) 1988 Society for Neuroscience $0270-6474 / 88 / 093360-16 \$ 02.00 / 0$
}

These observations suggest a developmental sequence in which dopamine-containing fibers invade the striatal anlage prior to forming distinct islandic foci and prior to the maturational events signaled by the production of CaM kinase II within the neurons and neuropil of future striosomes. Soon thereafter, patches of striatal neurons and neuropil begin to express this function-related protein kinase, and only then do dopamine-containing fibers form macroscopically visible dopamine islands in register with these patches. Increases in the concentration of synapses within dopamine islands follow this compartmentalization of striatal neurons and afferents. Maturation of future striosomes precedes maturation of extrastriosomal matrix for an extended developmental period.

The striking anatomical and histochemical mosaic of the striatum is, by now, well documented. It has been shown in adult mammals (including human) that the striatum is compartmentalized into at least 2 distinct subdivisions, the striosomes and the surrounding extrastriosomal matrix; and it is clear that this striosome/matrix architecture provides a framework upon which not only the intrinsic biochemistry but also the afferent and efferent connections of the striatum are organized (see Graybiel and Ragsdale, 1983; Gerfen, 1984; Graybiel, 1986). Ontogenctic studies of the striatum have shown that many elements of this basic compartmentalized framework are present during pre- and postnatal development (Golden, 1972; Olson et al., 1972; Tennyson et al., 1972; Butcher and Hodge, 1976; Ragsdale and Graybiel, 1979; Goldman-Rakic, 1981; Graybiel et al., 1981; Kent et al., 1982; Graybiel, 1984a, b; Graybiel and Chesselet 1984; Moon Edley and Herkenham, 1984; van der Kooy, 1984; Goedert el al., 1985; Graybiel and Newman-Gage, 1985; Nastuk and Graybiel 1985a, b; Newman-Gage and Graybiel, 1985, 1986; Newman-Gage et al., 1986; Gerfen, 1986; Lowenstein et al., 1986; Foster et al., 1987). Both dopamine-containing nigrostriatal afferents and striatal cells with particular birth dates are clustered from prenatal stages in "dopamine islands," the regions destined to become striosomes. As early as the beginning of the third trimester in the cat, the dopamine islands of the fetal striatum are clearly identified histochemically by their dense tyrosine hydroxylase (TH)-like immunoreactivity and strong AChE staining. They can also be recognized by the clustering of ${ }^{3} \mathrm{H}$-thymidine-labeled cells that have been pulse-labeled between embryonic days (E) 23 and 30 (Graybiel and Hickey, 1982). In the rat, striatonigral projection neurons have been shown to be clustered in the dopamine island regions prior to birth (Fishell and van der Kooy, 1985, 1987), and in the mon- 
key, prefrontal corticostriatal fibers terminate in relation to cell clusters during the last third of gestation (Goldman-Rakic, 1981). Finally, many neurotransmitter markers and receptor-related ligand binding sites have different distributions in the developing striosome and matrix compartments (e.g., Kent et al., 1982; Nastuk and Graybiel, 1985a; Murrin and Ferrer, 1984). Thus, in the developing striatum of several species, the forerunners of striosomes appear to be significant organizational features of striatal development.

Of fundamental importance is the issue of how these primary compartmental specializations are initially established. Apparently, the striatum does not have the simple "inside-out" maturation pattern that is characteristic of neocortex. There are several mechanisms, involving both intrinsic and extrinsic factors, that could produce a final clustered arrangement of cells and specific afferents (Graybiel and Hickey, 1982; Graybiel, 1984a; Marchand and Lajoie, 1986; Fishell and van der Kooy, 1987). It has been suggested that individual cells or groups of cells destined to be in dopamine island regions could follow specific migratory trails formed by glial guides or extracellular matrix, so that as a result of factors intrinsic to the striatum, clusters of "like" cells would be formed and mature in concert. In this situation, the clustered cells could attract or direct incoming afferents to the appropriately organized architectural compartments. Alternatively, postmitotic neurons generated during the striosomal time window could migrate at random into the nascent caudatal anlage, where they could passively become aggregated together by later-migrating neurons. Certain populations could be selectively stabilized by receiving afferent input, by establishing efferent connections or by becoming functionally active, while those failing to become stabilized would undergo cell death or possibly mature on a different schedule. Clearly, an interplay over time must occur between intrinsic and extrinsic factors in the development of the dopamine island/ striosomal labyrinths and the segregation of afferents with respect to this architecture. A key to understanding the initiation of these events, however, is learning whether striatal neurons become compartmentalized and begin to mature in response to their own schedule or whether this development occurs secondarily in response to an early-arriving, clustered dopamine island afferent population that innervates the nascent striatum.

In an effort to address this question, we have studied the developmental expression of immunohistochemical markers that identify antigens within nigrostriatal afferent fibers, within neuronal perikarya and neuropil, including postsynaptic densities, and within the membranes of synaptic vesicles. The first antiserum (6G9; Miller and Kennedy, 1986) is a marker for a multifunctional protein kinase within mature neurons, type II $\mathrm{Ca}^{2+}$ / calmodulin-dependent protein kinase (CaM kinase II). This enzyme is the most abundant protein kinase in the brain and is found only in neurons (Bennett et al., 1983; Ouimet et al., 1984; Schwartz and Greenberg, 1987). Primary substrates include not only itself, but also certain classes of microtubule-associated proteins, tubulin, synapsin 1, and a large number of other cellular peptides and proteins, including TH (Grab et al., 1981; Yamauchi and Fujisawa, 1981, 1982, 1983; Goldenring et al., 1983; Kennedy et al., 1983b; Schulman, 1984; Vuillet et al., 1984; LeVine III et al., 1985; Miller and Kennedy, 1986; Schwartz and Greenberg, 1987). At maturity, CaM kinase II is concentrated in the dendritic and perikaryal cytoplasm of forebrain neurons and is also found in presynaptic terminals. Furthermore, it is known to be the major postsynaptic density protein
(Kennedy et al., 1983a; Goldenring et al., 1984). CaM kinase II thus appears to be intimately involved in a number of activities within the neuron, including signal transduction (Erondu and Kennedy, 1985; Schwartz and Greenberg, 1987). A second antiserum, SV48 (Matthew et al., 1981), served to mark synaptic terminals in the developing striatum. SV48 specifically labels an integral membrane protein of synaptic vesicles and in the striatum is found only in synaptic terminals. Finally, an antiserum raised against $\mathrm{TH}$ was used to label dopamine-containing afferents of the striatum, which are known to express TH-like immunoreactivity early in development (Specht et al., 1981b). By comparing the times of appearance and the distributions of these 3 markers with immunohistochemical techniques, we hoped to pinpoint the first expression of a function-related neuronal marker in striatal neurons and neuropil in relation to the arrival of nigrostriatal fibers and to the onset of synaptogenesis. The findings, previously reported in brief (Newman-Gage and Graybiel, 1986; Newman-Gage et al., 1986), demonstrate a remarkable early compartmentalization of striatal neurons and neuropil expressing CaM kinase II that precedes comparable macroscopic clustering of dopamine-containing afferents and the formation of synaptic clusters.

\section{Materials and Methods}

Six fetal cats at E 32, 36, 46, 54, 4 kittens at postnatal (P) days 1 and 9 , and 2 adult cats from the laboratory breeding colony were used in this study. Pairs of cats were caged together for mating overnight; mating usually occurred within the first few hours. The day after mating was considered E1. Kittens were usually born at night after a gestational period of approximately $65 \mathrm{~d}$, and the following day was considered P1.

Postnatal animals were anesthetized with intraperitoneal (kittens) or intravenous (adults) injections of sodium pentobarbitol (Nembutal). Anesthetized fetal kittens were obtained by sterile laparotomy on the morning of the appropriate gestational day. All animals were transcardially perfused for $5 \mathrm{~min}$. The perfusate consisted of $3.0 \%$ paraformaldehyde, $0.34 \% d . l$-lysine, and $0.05 \%$ periodate in $0.1 \mathrm{M}$ phosphate buffer at room temperature and $\mathrm{pH}$ 7.3-7.4. Whole brains were removed immediately and placed in fresh fixative at $4^{\circ} \mathrm{C}$ for $1-3 \mathrm{~d}$. The brains were then washed and infiltrated with buffer containing $8.0 \%$ dextrose at $4^{\circ} \mathrm{C}$ for $2-3 \mathrm{~d}$.

Serial vibratome sections $(70 \mu \mathrm{m})$ were collected from most brains and processed for light microscopic immunohistochemical identification of antigen (and for electron microscopic observations to be described in a separate report). Some tissue was frozen and cut at $30 \mu \mathrm{m}$ on a sliding microtome for demonstration of reaction product solely at the light microscopic level. Sections were pretreated with ethanol solutions in an ascending and then a descending series of concentrations $(10,20,30,40 \%)$ using Tris buffer as the diluent and then incubated in primary antibody solution. For sections from the adult brains, the first ethanol solution also contained $2.0 \%$ hydrogen peroxide to suppress endogenous peroxidase activity. TH antiserum was diluted 1:500 (Eugenetech, Allendale, $\mathrm{NJ}$ ); antiserum recognizing the alpha subunit of type II calcium/calmodulin-dependent protein kinase (6G9) was diluted 1:400 (gift from Dr. Mary Kennedy), and the antiserum recognizing a $65,000 \mathrm{Da}$ integral membrane protein found exclusively on synaptic vesicles (SV48) was dilutcd 1:1 (gift from Dr. William Matthcw). All antisera were diluted with $0.05 \mathrm{M}$ Tris buffer, and the final solution contained $1.0 \%$ normal cat serum and $1.0 \%$ normal goat serum. In some vials, $0.01 \%$ Triton $\mathrm{X}-100$ was also added to the primary antiserum solution. Sections were incubated for $18-24 \mathrm{hr}$ at $4^{\circ} \mathrm{C}$, then washed in $0.05 \mathrm{M}$ Tris saline buffer for $1.5 \mathrm{hr}$ with several changes of buffer. Secondary antisera were diluted 1:10 with the same diluent as above, using goat anti-rabbit IgG (Antibodies Incorporated, Davis, CA) for TH and goat anti-mouse IgG, IgM (Boehringer Mannheim, Indianapolis, IN) for SV48 and CaM kinase II. After $3.5 \mathrm{hr}$ in secondary antiserum, tissue sections were again washed for $1.5 \mathrm{hr}$ in $0.05 \mathrm{M}$ Tris saline buffer with several changes. Rabbit or mouse peroxidase-antiperoxidase antisera (Sternberger-Meyer, Jarretsville, MD) were diluted 1:50, and sections were incubated in the dark for $3.5 \mathrm{hr}$. Sections were then washed 


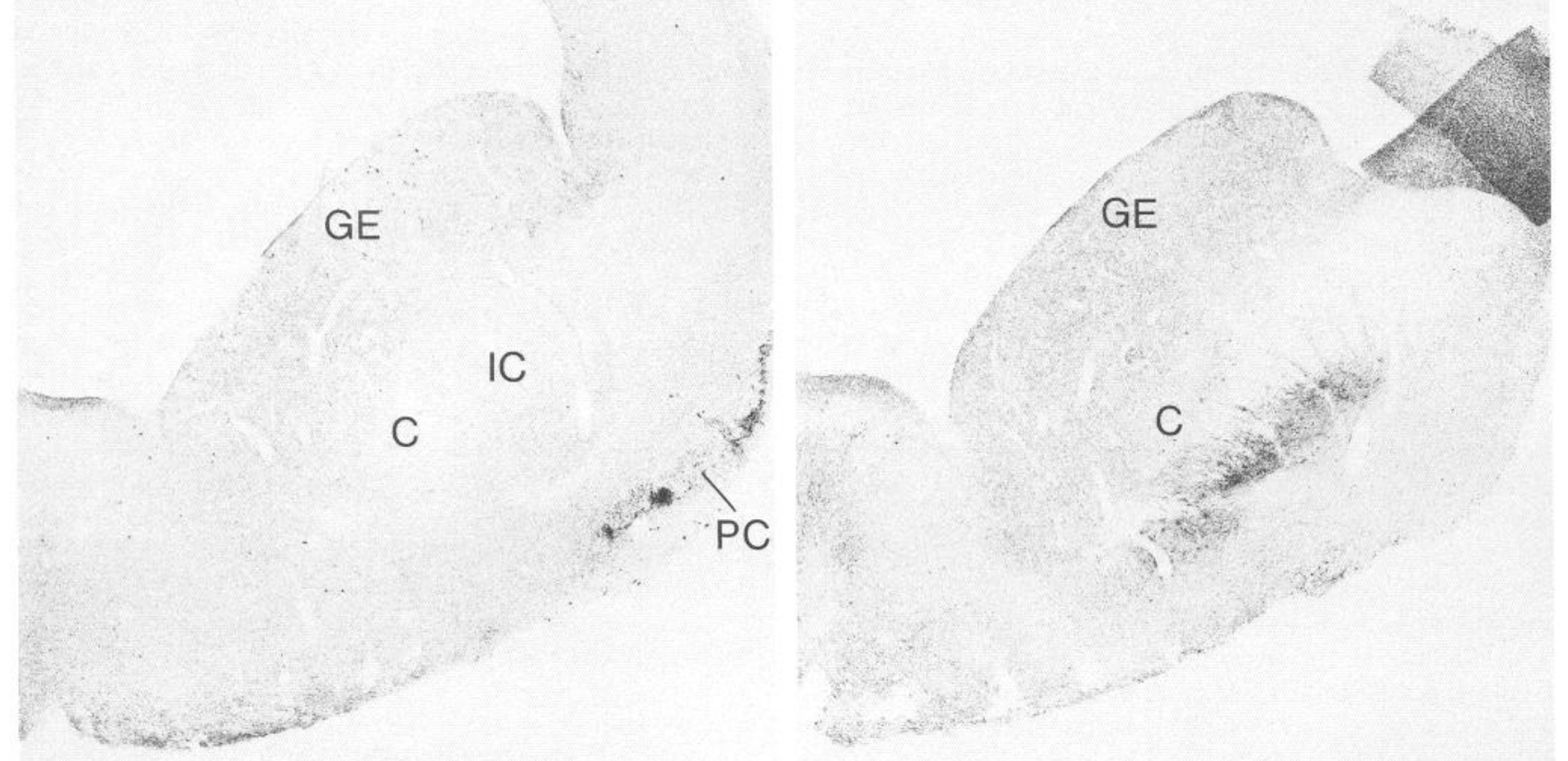

C
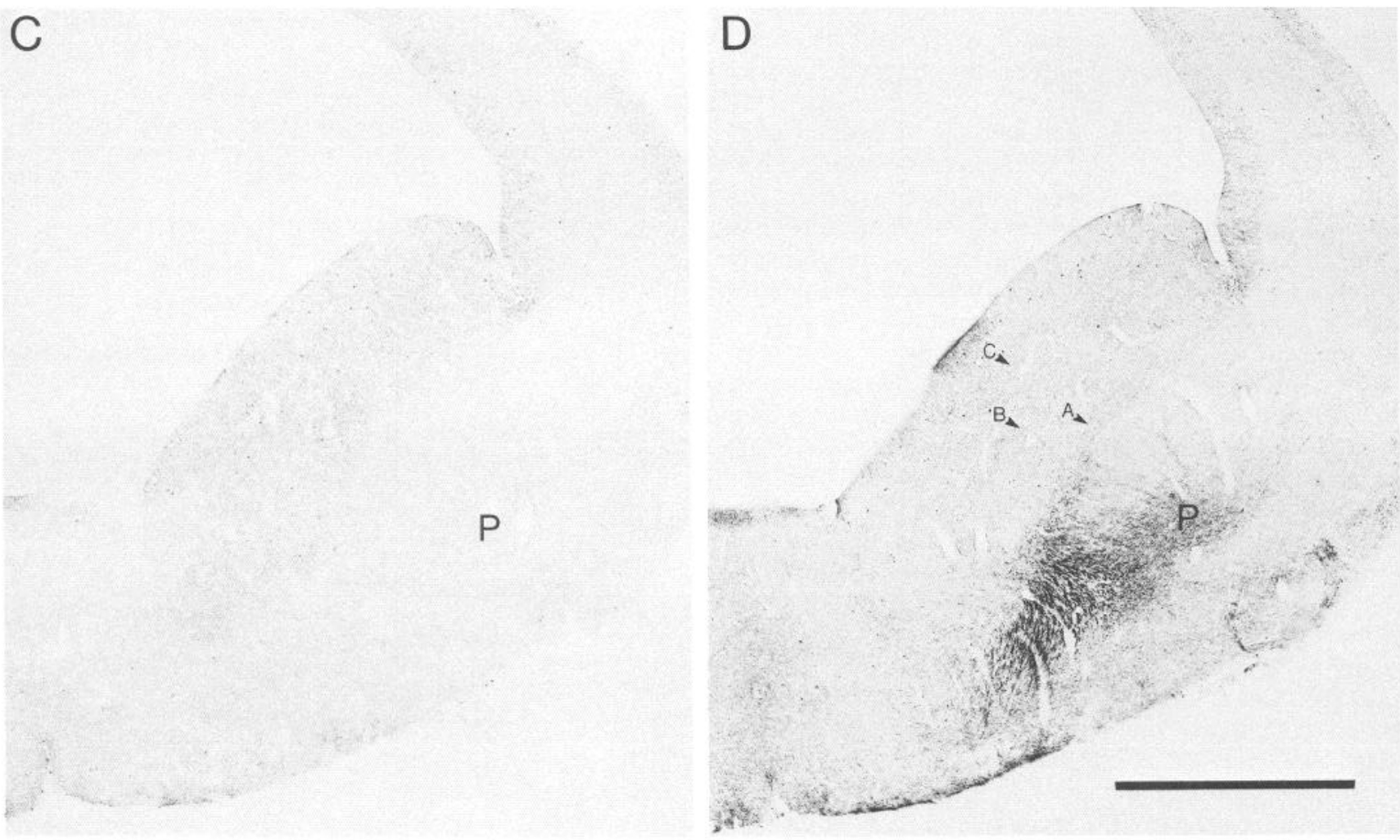

Figure 1. Serial $30 \mu \mathrm{m}$ sections from the caudal third of the striatum in an E32 cat fetus. For a guide to the anatomical organization of the developing forebrain, see Figure $3 A^{\prime}, A$, CaM kinase II-like immunoreactivity is most concentrated in piriform cortex $(P C)$. The striatum $(C, P)$ is only very weakly immunoreactive, and the ganglionic eminence $(G E)$ is unstained. The apparent optical density of the ganglionic eminence in these and Figures 3-5 is constant and artifactual, probably resulting from refracted light scattering by the radially oriented cells and processes in this zone. $B, \mathrm{AChE}$ staining has a prominent distribution in the putamen and the extreme lateral edge of the caudate anlage. Its distribution appears to parallel that of the TH-like immunoreactivity (in $D$ ). $C$, SV48 immunostaining is absent from the striatum. $D$, Marked TH-like immunoreactivity can be seen in the putamen and the cell bridges spanning the internal capsule (IC), and invades the lateral edge of the caudate anlage. Small labeled arrowheads refer, respectively, to regions shown at higher magnification in Fig. $2 A-C$. $C$, Anlage of caudate nucleus; $P$, putamen. Scale bar, 1 mm. 
in $0.05 \mathrm{~m}$ Tris saline buffer, followed by several changes of $0.1 \mathrm{M}$ Tris buffer for a half-hour and incubated in 3.4\% diaminobenzidine (Sigma, St. Louis) for $15 \mathrm{~min}$. Hydrogen peroxide was added to a final concentration of $0.27 \%$ for times ranging from 8 to $20 \mathrm{~min}$, and reactions were stopped by washing the sections in $0.1 \mathrm{M}$ Tris buffer. Control sections were treated in the same manner except that antibody was omitted from the primary incubation solution. Sections were then rinsed, mounted on subbed slides, and coverslipped for light microscopy.

Some sections were processed for AChE histochemistry instead of TH-immunohistochemistry by a modified Geneser-Jensen and Blackstad method (Geneser-Jensen and Blackstad, 1971; Graybiel and Ragsdale, 1978). TH-like immunoreactivity and AChE histochemistry have previously been shown to be coextensive in dopamine islands during fetal cat development (Graybiel et al., 1981).

\section{Results}

\section{Prenatal development}

E32. At the halfway point of gestation, the embryonic kitten brain has a very small but identifiable striatum. In sections stained with the antibody to CaM kinase II, the striatum appeared to be only very weakly stained (mid- and caudal sections) or unstained (rostral sections) (Fig. 1A). No immunoreactivity was visible in the ganglionic eminence. Occasional cell bodies in the putamen, and fewer at the lateral edge of the caudate nucleus, appeared to express minute amounts of $\mathrm{CaM}$ kinase II-positive reaction product. Except for a small part of cortex ventral to the presumptive cingulate gyrus (the anlage of the indusium griseum), and the piriform cortex, no other regions of the rostral forebrain yet expressed this $\mathrm{Ca}^{2+} /$ calmodulin-dependent protein kinase-like immunoreactivity.

In contrast to the weak CaM kinase II staining in the E32 striatum, there was marked TH-like immunoreactivity. Many stained fibers appeared within the putamen, internal capsule, and the anlage of the caudate nucleus (Fig. 1D). Middle and caudal parts of the putamen were densely infiltrated with labeled fibers; the rostral part of the putamen and the caudate nucleus contained fewer fibers.

TH-positive fibers could often be followed for long distances within the striatum. In the caudate nucleus, many of these fibers appeared to course parallel to each other and parallel to or at only a slight angle away from the internal capsule (Fig. 2A). Occasional fibers were found deep within the anlage of the caudate nucleus (Fig. $2 B$, large arrows), where they approached or appeared to enter the germinal zone (ganglionic eminence) (Fig. $2 C$, large arrows). TH-positive elements did not appear to have a clustered or islandic arrangement. Rather, they seemed to follow broad developmental gradients in a homogeneous or nearly homogeneous fashion from lateral and ventral to dorsal and medial within the caudate nucleus and, in general, from caudal to rostral in both the caudate nucleus and the putamen.

AChE staining was present in the same regions as $\mathrm{TH}$-like immunostaining (Fig. $1 B$ ). At high light microscopic magnifications, no clearly defined fibers stained for AChE could be seen, in contrast to the sharp delineation of fibers by $\mathrm{TH}$ immunostaining. Instead, there were small crystalline niduses visible in the AChE-stained sections that appeared at intervals within the AChE-stained zones.

No immunostaining by SV48 was found in the E32 striatum (Fig. 1C). The only reaction product in the embryonic forebrain was pale, and this was found in the piriform cortex and olfactory tubercle. Thus, at this age it appeared that very little synaptogenesis had yet occurred within the striatum.

$E 36$. Much of the fetal forebrain at the level of the striatum was again unstained or only weakly immunostained with the 3 antibodies or with AChE histochemistry. Only the striatum itself

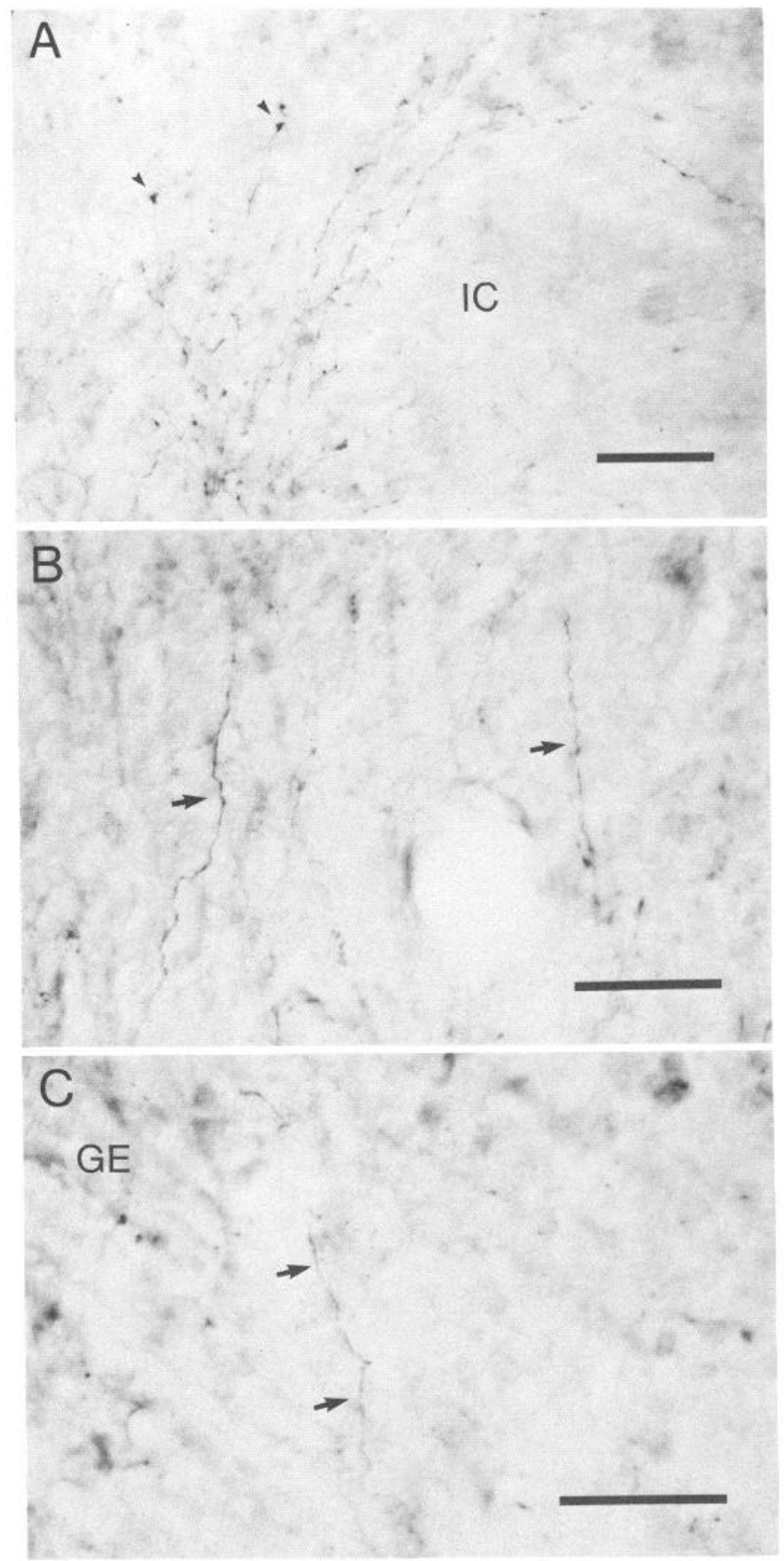

Figure 2. High-magnification views of TH-immunostained section shown in Figure $1 D$. Dorsal is at the top. Large arrows indicate examples of TH-positive fibers. $A$, Immunoreactive fibers often course parallel to or slightly angled away from the dorsolateral to ventromedial axis of the internal capsule $(I C)$. Several fibers appear to terminate in growth cone-like profiles (arrowheads). $B$, Scattered TH-positive fibers typically found deeper within the caudate anlage. $C$, Occasional labeled fibers lie within the ganglionic eminence (see Specht et al., 1978). None of these could be traced unequivocally back to origins in the bundles of fibers at the lateral edge of the caudate nucleus anlage. $C$, Anlage of caudate nucleus; $G E$, ganglionic eminence; Scale bar, $0.05 \mathrm{~mm}$.

was consistently labeled with all 3 antibodies at E36. The distribution of CaM kinase II-like immunoreactivity was most striking (Fig. $3 A$ ). In the putamen, especially at its periphery, there were densely immunostained patches in a weakly stained matrix. In some sections the lateral margin of the putamen 


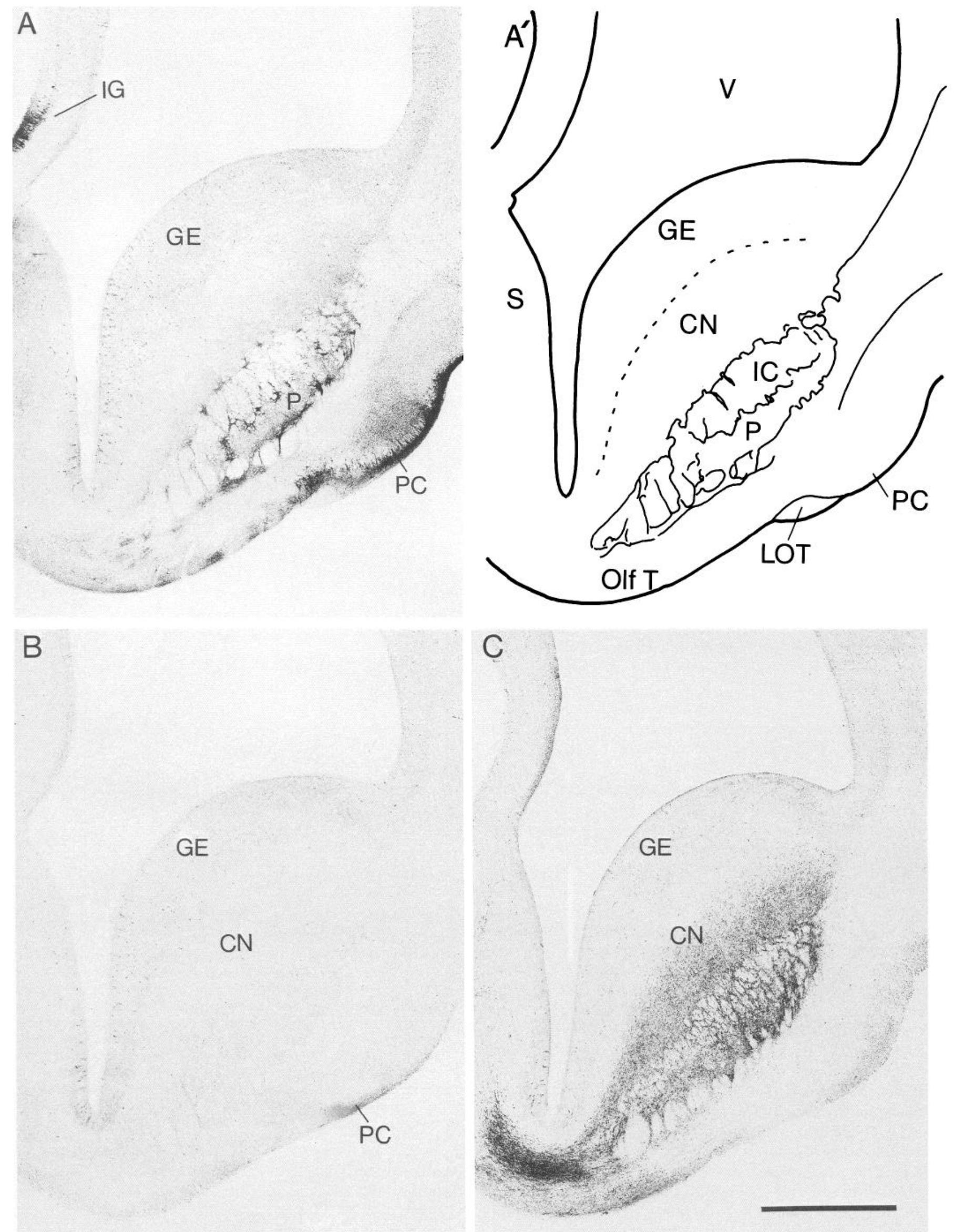


presented a nearly continuous band of CaM kinase II-like immunoreactivity. The caudate nucleus also had densely stained patches of CaM kinase II-like immunoreactivity at its lateral edge abutting the internal capsule. The patches were about 0.07 $\mathrm{mm}$ wide and tended to be regularly spaced at about $0.16 \mathrm{~mm}$ intervals. A few striatal cell bodies within the patches were clearly immunostained, though none were as distinctly delineated by immunostaining as those found in the piriform cortex and indusium griseum. Some immunoreactive fibers and varicosities could be seen within the patches but much of the islandic immunostaining appeared to be diffusely distributed in the neuropil of the patches, so that the identity of individually stained elements could not be established. Weak immunostaining in the matrix extended medially, to approximately onequarter to one-third the distance from the internal capsule to the ventricle (Fig. $3 A$ ). The ganglionic eminence was unstained.

TH-like immunoreactivity in the E36 forebrain was largely confined to the caudate nucleus, the putamen, and parts of the nucleus accumbens. Moderate TH-like immunoreactivity was distributed throughout the putamen, in the striatal cell bridges infiltrating the internal capsule, and in the lateral one-half to two-thirds of the caudate nucleus. In contrast to CaM kinase II-like immunoreactivity, TH-like immunoreactivity appeared to have a nearly homogeneous distribution. There were some hints of islandic concentrations of immunostaining, however, and these were somewhat more obvious in the putamen than in the caudate nucleus (Fig. 3C). This faint enhancement of THlike immunostaining with in islands was more apparent at middle and caudal levels. At higher magnification, reaction product was seen in punctate chains (typical of TH-like immunoreactivity), many of which terminated in large growth cone-like irregular shapes similar to those seen at E32 (Fig. 2).

Though both CaM kinase II-like and TH-like immunostaining were clearly present in the E36 striatum, synaptic vesicle protein-like immunoreactivity was very weak in both the putamen and the caudate nucleus. Neuropil distinctly stained for SV48 was found only in the superficial layer of piriform cortex near the lateral olfactory tract (Fig. $3 B$ ).

E46. By E46, CaM kinase II-like immunoreactivity in the striatum, limbic cortex, and septum had intensified (Fig. 4A), but there continued to be little reaction product elsewhere in the rostral forebrain. In the striatum, dense patches of CaM kinase II-like immunoreactivity appeared in the putamen, especially at its periphery but also the interior of the nucleus. The most striking change from the E36 pattern of CaM kinase IIlike immunoreactivity was in the caudate nucleus (Fig. 4A). Distinct CaM kinase II-positive islands appeared not only at the most lateral edge of the nucleus but also through the interior one-half to two-thirds of its width. Scarcely any immunostaining appeared in the nonislandic matrix of the striatum, and none was detectable in the ganglionic eminence.

Classic TH- and AChE-positive dopamine islands were present in the lateral two-thirds of the caudate nucleus, especially dorsally. The ganglionic eminence was unstained. Ventrally there were TH-positive zones in the nucleus accumbens, but the olfactory tubercle was only weakly stained. In sharp contrast to the situation at E36, by E46 the AChE-positive and TH-positive islands in the striatum could be as clearly delineated as the CaM kinase II-like immunoreactive islands (Fig. 4, $B, D$ ). In the putamen, the darkest AChE staining and TH-like immunoreactivity was along the periphery of the nucleus, as was true for CaM kinase II-like immunoreactivity.

E46 presented the first age sampled at which there was unequivocal staining for SV48-like immunoreactivity in the striatum (Fig. 4C). The striatal regions stained were strictly confined to the island systems of the putamen and the caudate nucleus. The SV48-positive patches coincided with TH- and AChE-positive and CaM kinase II-immunoreactive patches in adjacent sections. The ganglionic eminence was unstained. Elsewhere in the rostral forebrain, SV48-like immunoreactivity was minimal except in the piriform cortex.

The patterns just described for the E46 striatum were recognizable in the E54 samples (not illustrated), though for all markers, immunoreactivity or histochemical staining had intensified both in the islandic system and in the nonislandic matrix.

\section{Postnatal development}

$P 1$. Elaboration of the striatal dopamine island system continued throughout prenatal development and into the early postnatal period. At P1, extensive neuron-cluster systems were revealed by $\mathrm{CaM}$ kinase II-like immunoreactivity in both the caudate nucleus and the putamen (Fig. $5 A$ ). As at younger ages, the CaM kinase II island pattern was in register with the AChEpositive and TH-positive island system. CaM kinase II-positive patches now appeared throughout the entire mediolateral and dorsoventral extent of the caudate nucleus. Dorsal patches were more distinct and somewhat smaller than their ventral counterparts, and, in contrast to those situated ventrally, the dorsal CaM kinase II-positive patches occasionally were partially or completely surrounded by thin unstained rims that appeared even paler than the matrix. Immunostaining for CaM kinase II in the nonislandic matrix had increased to a moderate intensity. CaM kinase II-like immunoreactivity in the ventral striatum continued to be distinctly inhomogeneous and in the septum appeared to be nearly homogeneous. In addition, laminar immunostaining of the cortex was now evident (Fig. $7 A$ ).

TH-like immunoreactivity at Pl appeared in the typical dopamine island pattern, with islands throughout the full extent of the caudate nucleus. As with CaM kinase II immunostaining, the dorsal islands were more distinct and somewhat smaller than the ventral islands (Fig. $5 C$ ), though they rarely had pale rims. Staining intensity of the nonislandic matrix had also increased from prenatal levels, especially dorsolaterally. The ventral striatum was inhomogeneously stained. No other significant

Figure 3. Coronal $60 \mu \mathrm{m}$ sections from the middle third of the E36 striatum illustrating $(A)$ CaM kinase II-positive immunoreactivity, $(B)$ SV48like immunoreactivity, and $(C)$ TH-like immunoreactivity. $A$, CaM kinase II-like immunoreactivity is concentrated in 3 regions of the rostral forebrain: indusium griseum $(I G)$, striatum $(C N, P)$, and piriform cortex $(P C)$. Both the caudate nucleus and putamen have a discontinuous distribution of reaction product. $A^{\prime}$, Reference line drawing of the section shown in $A$, depicting topography of the fetal cat forebrain at the level of the striatum. $B$, SV48-like immunostaining is detectable only in piriform cortex $(P C)$. $C$, Widespread and nearly homogeneous distribution of TH-positive fibers in the striatum. $C N$, Caudate nucleus; $G E$, ganglionic eminence; $L O T$, lateral olfactory tract; $I C$, internal capsule; $O l f T$, olfactory tubercle; $P$, putamen; $S$, septum; $V$, ventricle. Scale bar, $1 \mathrm{~mm}$. 

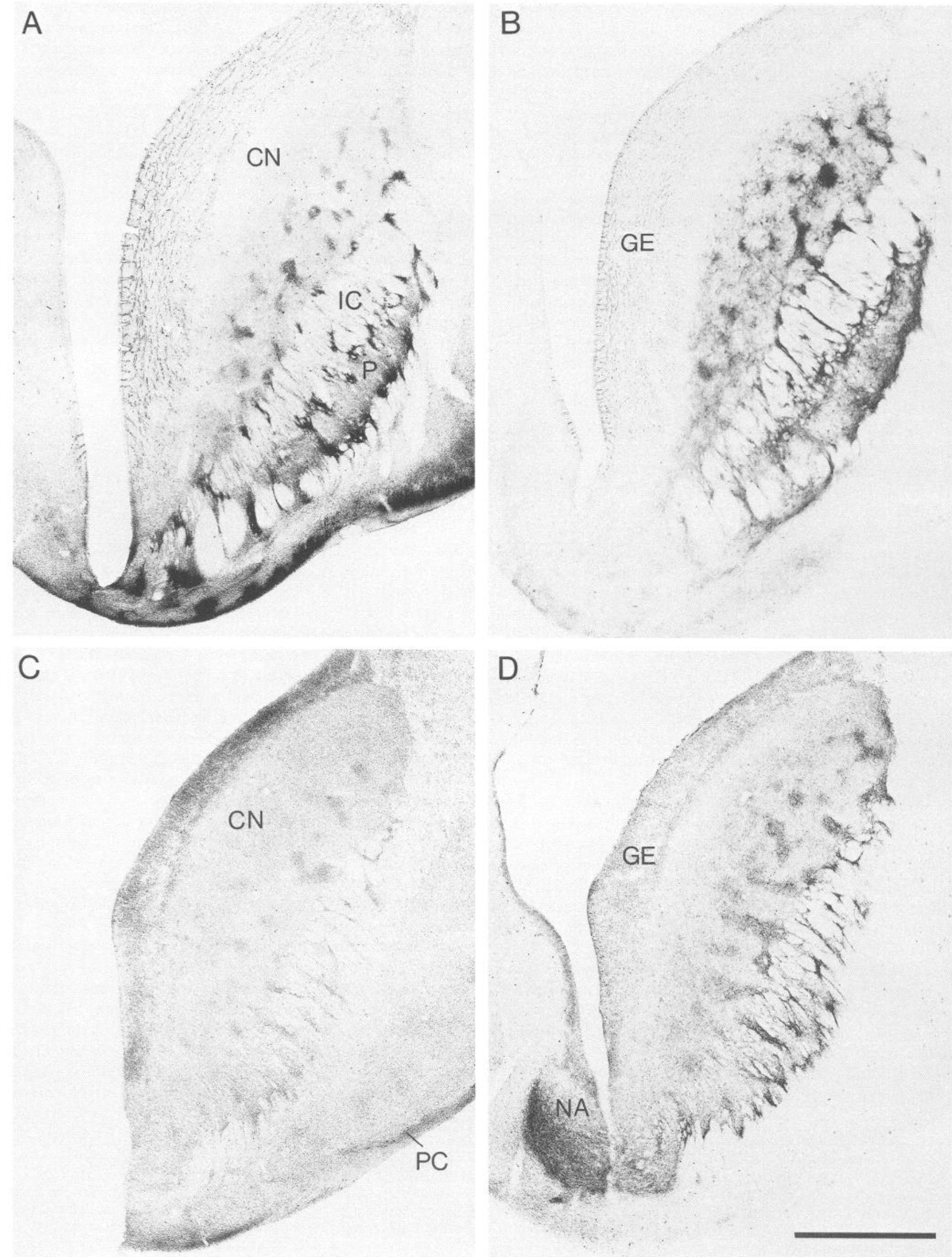
concentrations of TH-like immunostaining were found in the rostral forebrain at this age.

The SV48-immunoreactive islands in the caudate nucleus and putamen appeared to be coextensive with those stained for THlike and CaM kinase II-like immunoreactivity (Fig. $5 B$ ). The concentration of SV48-like reaction product in the matrix of the caudate nucleus had increased to moderate levels, and in the putamen staining of the matrix had become so dark that it was difficult to distinguish islands clearly. SV48-like immunoreactivity in the ventral striatum was again inhomogeneously distributed and distinct concentrations of SV48-like reaction product were found in the islands of Calleja. Outside the striatum, SV48-like immunostaining had now become concentrated in the molecular layer of the neocortex and in both the molecular layer and layer III of piriform cortex (Fig. 7B).

$P 9$. Postnatal day 9 was representative of the transitional phase of striatal development in the cat. The TH-positive dopamine islands were gradually fading in relation to the increasingly densely stained matrix. All 3 immunohistochemical markers and AChE staining revealed an increased staining of the nonislandic matrix relative to that found in the dopamine island locales. The staining patterns at this age were complex and appeared to follow several different spatial and temporal gradients (to be described in a separate account).

\section{Patterns of immunoreactivity at adulthoood}

The mature caudate nucleus and putamen were characterized by a relatively homogeneous distribution of intense $\mathrm{CaM}$ kinase II-like immunoreactivity, whereas both the olfactory tubercle and the nucleus accumbens, and also the bed nucleus of the stria terminalis, continued to exhibit slight inhomogeneities in immunostaining (Fig. 6A). The dense staining in the striatum, and of the cellular layers of the neocortex (Fig. 7C), contrasted sharply with the pale appearance of subcortical white matter, including the corpus callosum, internal capsule, anterior commissure, and intrastriatal fiber bundles (Fig. 6A). Most, if not all, neuronal perikarya in the rostral forebrain appeared to contain at least moderate amounts of CaM kinase II-like reaction product, and a significant amount of CaM kinase II-like immunostaining was also located in regions of neuropil.

SV48-like immunoreactivity was dense in the striatum and elsewhere in subcortical and cortical parts of the forebrain, excluding white matter (Figs. $6 C, 7 D$ ). No strikingly pale or dense zones were present in the caudate nucleus or putamen, but the distribution of reaction product did appear mottled. Sometimes the paler regions could be aligned with striosomes, detected as pale zones in adjacent sections stained for AChE activity. However, the figures in the SV48-like immunostaining did not exactly match the striosomes in size or shape, and they were difficult to detect. Reaction product had a punctate appearance and cell bodies were distinctly pale (Fig. $7 D$ ). The SV48-like immunoreactivity in the ventral striatum and olfactory tubercle was inhomogeneous, with particularly prominent staining of the islands of Calleja.

TH-like immunoreactivity was very dense in the striatum (Fig. 6D). Its distribution was inhomogeneous in the olfactory tubercle and the nucleus accumbens but was only slightly inhomogeneous in appearance in the putamen. Immunostaining in the caudate nucleus of the adult was characterized by distinct pale zones that lay in a more densely immunoreactive matrix, and these pale zones corresponded to AChE-poor striosomes seen in adjacent sections (Fig. 6B). The TH-poor striosomes tended to have discrete borders dorsally but were more difficult to outline ventrally. A similar finding of TH-poor striosomes in the adult human striatum has been reported recently (Ferrante et al., 1987; Graybiel et al., 1987).

\section{Discussion}

The findings presented here suggest that in the dopamine island system, compartments composed of CaM kinase II-positive neurons and neuropil provide an early cytoarchitectural framework upon which dopaminergic afferents become concentrated, within which concentrated synaptogenesis begins, and through which some of the earliest neuronal circuits of the striatum may become established. Our observations also suggest that the expression of immunoreactivity for CaM kinase II may be used as an index of maturation for neurons and neuronal systems in the striatum and in the mammalian forebrain generally. This early expression does not, in itself, point to the onset of any particular intracellular process. However, given the wide variety in cellular substrates of CaM kinase II, its apparent involvement in the physiological activity of mature neurons, and its special association with synapses, both presynaptically (synapsin 1 is a major substrate; Kennedy et al., 1983b) and postsynaptically (it is the major postsynaptic density protein; Kennedy et al., 1983a; Goldenring et al., 1984), it seems possible that its expression during development in postmigratory neurons signals maturational events associated with the acquisition of functional adult characteristics. The significance of this conclusion for understanding the development of the striatum rests in the selective early expression of CaM kinase II in the future dopamine island/ striosome system of the caudate-putamen and in localized parts of the ventral striatum.

\section{Formation of dopamine islands}

No light microscopic study in a mammalian brain can establish unequivocally the precedence of one or another class of elements in guiding the cascade of events occurring in the development of a particular region. There are too many elements, and individual elements are too difficult to detect. However, in the study reported here, it was striking that (1) numerous, apparently diffuscly distributed, TH-positive fibers appeared in the striatal

Figure 4. Two pairs of sections from different animals at middle $(A, B)$ and rostral $(C, D)$ levels of the E46 striatum. $A$, CaM kinase II-like immunoreactivity $(70 \mu \mathrm{m}) . B$, AChE staining $(70 \mu \mathrm{m}) . C$, SV48-like immunoreactivity $(60 \mu \mathrm{m}) . D$, TH-like immunoreactivity $(60 \mu \mathrm{m})$. E46 marked the first appearance of definitive SV48-like immunostaining in the striatum in the sample of fetal brains studied. The immunostaining, though pale, is distinctly islandic. The contrast of this image was enhanced photographically to increase the visibility of the pale islands. This enhancement also darkened the artifact in the ganglionic eminence $(G E)$, which was devoid of reaction product in this and all other sections. Staining with other markers is further heightened in regions previously stained at the younger ages, and staining has also extended farther medially, away from the internal capsule $(I C)$. The labyrinthine nature of the dopamine island architecture can be appreciated in these sections (separated by $60-70 \mu \mathrm{m}$ ) by overlapping tracings of them: Islands of one section are connected via immunopositive bridges to islands in the next section. In tracings of adjacent pairs, the markers are in obvious registration. $C N$, caudate nucleus; $N A$, nucleus accumbens; $P$, putamen; $P C$, piriform cortex. Scale bar, $1 \mathrm{~mm}$. 

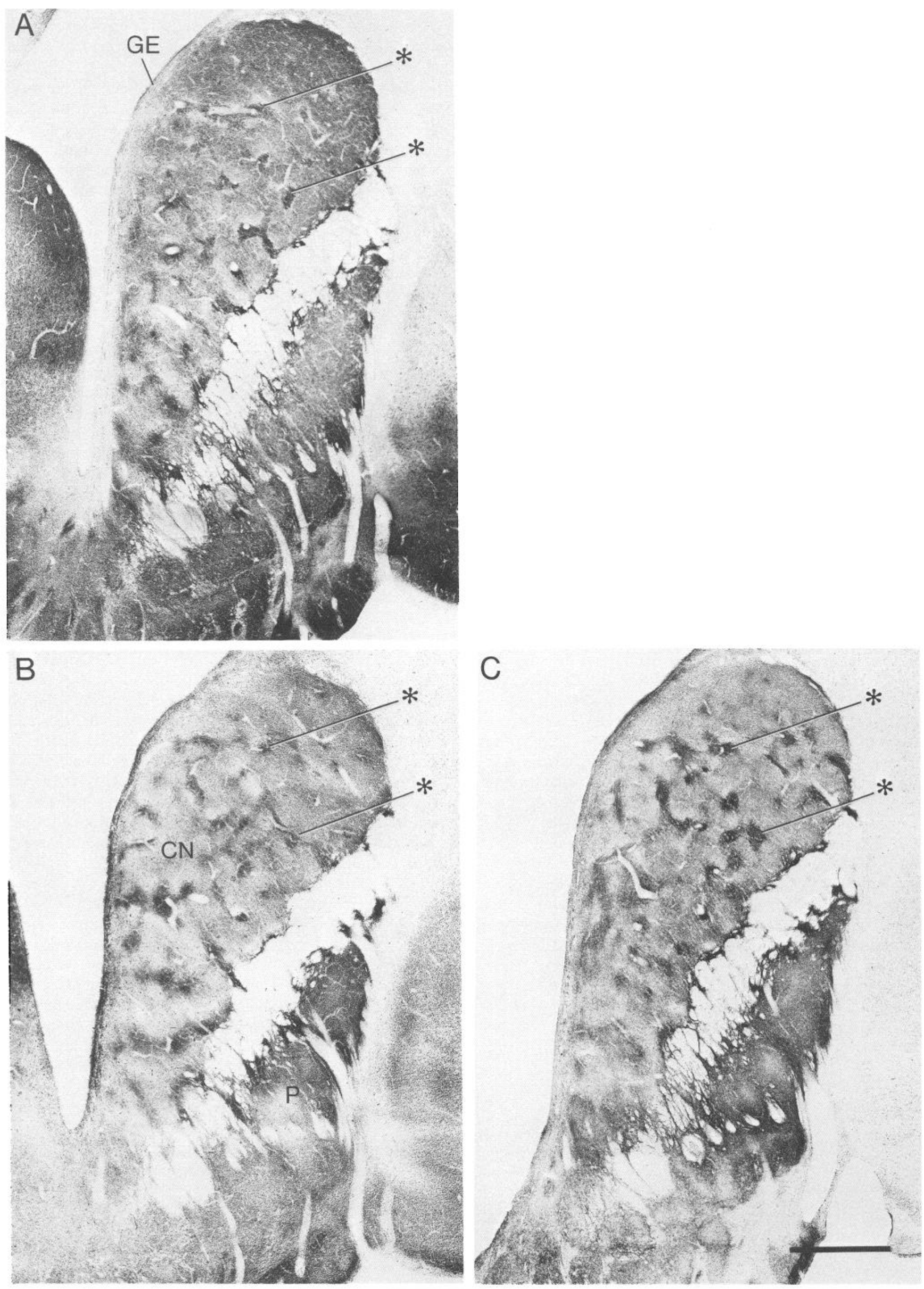
anlage before cells destined to become islandic neurons of the striatum began to express detectable levels of CaM kinase II, and (2) when CaM kinase II-like immunoreactivity did appear, it was distinctively compartmentalized, whereas the earliest distribution of TH-positive fibers in the same striatal regions still appeared nearly homogeneous. At the earliest time of CaM kinase II expression, much of the staining in the patches seemed to be associated with neuropil, and individually distinct, intensely immunoreactive cell bodies were rare. It is possible that part of the CaM kinase II detected was enzyme expressed only in a subset of the TH-positive afferents and/or in as yet undiscovered carly-arriving afferents from sources other than the substantia nigra. However, the presence of distinct $\mathrm{CaM}$ kinase IIpositive patches, containing labeled perikarya and neuropil, in an unlabeled matrix known to contain a complement of THpositive afferents qualitatively similar to that in the patches argues for an intrinsically based identity of some elements within the patches. We therefore conclude that, in addition to possible subsets of axons, the islandic distribution of CaM kinase IIimmunoreactivity reflects differentially early enzyme expression in a distinct population of striatal neurons during prenatal development.

There were many CaM kinase II-negative cells and associated neuropil in the striatal anlage between the CaM kinase II-positive patches. Conceivably, these cells were nonimmunoreactive because they were nonstriatal neurons or glia migrating through towards other target regions. This could not have been so for all the unlabeled cells, however. $\Lambda \mathrm{t}$ later ages (i.e., E46), when most matrix cells have been generated (unpublished observations), cellular CaM kinase II immunostaining within the matrix was still minimal. Moreover, we did not see any $\mathrm{CaM}$ kinase II-positive neurons in the ganglionic eminence or in the medial part of the caudate nucleus, a region through which recently postmitotic cells migrate.

The fact that CaM kinase II-like immunoreactivity was distinctly clustered while TH-like immunoreactivity was nearly homogeneously distributed implies that not all striatal cells exposed to the influence of $\mathrm{TH}$-positive fibers initially respond with production of this rather ubiquitous enzyme of forebrain neurons. Therefore, even if incoming dopamine-containing afferents are necessary for initiating certain stages of neuronal development, they may not be sufficient to do so in all neurons. The simplest interpretation of the evidence presented here is that the formation of discrete dopamine islands composed of TH-positive nigrostriatal afferents, although a hallmark of striatal development, is not the primary event that induces the development of the islandic arrangement of early CaM kinase IIpositive striatal neurons. Again, the occurrence of an occasional early or "pioneer" TH afferent would have been undetectable in our study, so that our conclusions are based upon observations above a single-fiber threshold; and we did not test for the possibility that other afferent fiber systems had reached the striatum during an early phase of islandic development. The crisp patching of CaM kinase II-like immunoreactivity before comparable crisp clustering of the earliest known striatal afferents- the dopamine island fibers-nevertheless suggests that factors intrinsic to the striatum and determining neuronal position may be critical in establishing striosomal compartmentalization.

An accumulating body of evidence supports the idea that the neurons of the dopamine island/striosome system are a distinctive population of cells whose maturational schedules and ultimate positions within the striatum may be independent of dopamine-containing afferents and may even be determined prior to leaving the proliferative zone. First, neurons destined to lie in the dopamine islands/striosomes are born during a restricted time window of development (Graybiel and Hickey, 1982; Graybiel, 1984b; Fishell and van der Kooy, 1987), and this time window precedes the birth times for most neurons of the nonislandic (extrastriosomal) matrix (Graybiel, 1984a; Fishell and van der Kooy, 1987; van der Kooy and Fishell, 1987; see also Bayer, 1984; Marchand and Lajoie, 1986). Accordingly, one of the distinctions between these 2 cell compartments is determined and coded in terms of heterochroneous generation schedules; and because of their early generation, islandic cells may lead matrix cells through a protracted period of striatal development. As the date of generation and the final position of a neuron appear to be closely linked, it is possible that the early-generated islandic/striosomal cells play a pivotal role in the establishment of the compartmental architecture of the striatum.

Further evidence comes from study of another "neuronal response" enzyme: DARPP-32 (dopamine and adenosine 3':5'monophosphate-regulated phosphoprotein; Foster et al., 1987). Phosphorylated DARPP-32 is a phosphatase inhibitor present in D1 dopaminoceptive neurons (Walaas et al., 1983; Hemmings et al., 1984). It is thought to potentiate postsynaptic messenger interactions (see review by Nestler et al., 1984). Foster and his coworkers have found that the appearance of immunohistochemically detectable DARPP-32 in striatal neurons of the rat predates the arrival of an apparently homogencous dopaminergic innervation by $1-2 \mathrm{~d}$ and that the subsequent development of distinct clusters of DARPP-32-positive cells predates the clustering of dopamine-containing fibers into islands. Thus, 2 functionally distinct enzymes, a protein kinase and a phosphatase inhibitor, are expressed in early-generated cell clusters prior to the formation of clear TH-positive afferent fiber inhomogeneities. Foster et al. (1987) suggest that the expression of DARPP-32 by presumptive D1-dopaminoceptive neurons could attract and/or selectively stabilize later-arriving dopamine-containing afferents to establish this dopaminergic architecture. If, as argued above, a consequence of early CaM kinase II expression relates to early functionality of the island regions, these findings would together provide strong support for the idea that the islandic features characteristic of striatal ontogeny have crucial functional as well as developmental consequences.

The suggestion that dopamine island cell clustering is not solely dependent upon afferent influences is consistent with experiments in which potential afferents from the neocortex have been removed (Lanca et al., 1986) or in which the dopaminergic receptor antagonist haloperidol was administered prenatally

Figure 5. Serial $70 \mu \mathrm{m}$ sections through the $\mathrm{P} 1$ striatum. $A$, CaM kinase II-like immunoreactivity. $B$, SV48-like immunostaining. $C$, TH-like immunostaining. The striatum has increased dramatically in size, and concomitantly, the ganglionic eminence $(G E)$ has shrunken to a thin rim at the medial edge of the caudate nucleus. The characteristic features of the dopamine island system can be clearly seen with all 3 immunostains, although the staining of the matrix has intensified. The tips of the lines marked by asterisks are in exact register in each section. $C N$, Caudate nucleus; $P$, putamen. Scale bar, $1 \mathrm{~mm}$. 

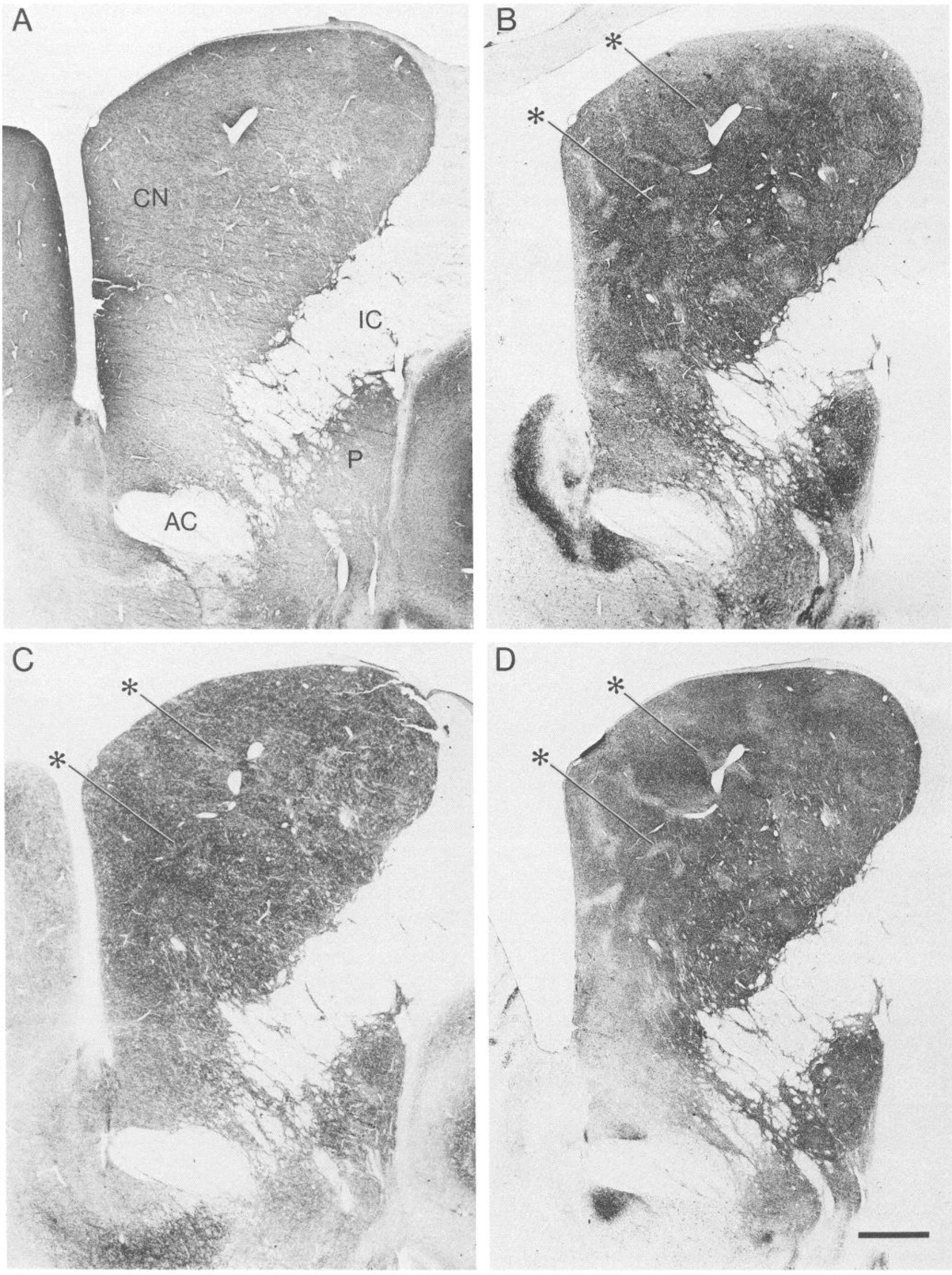

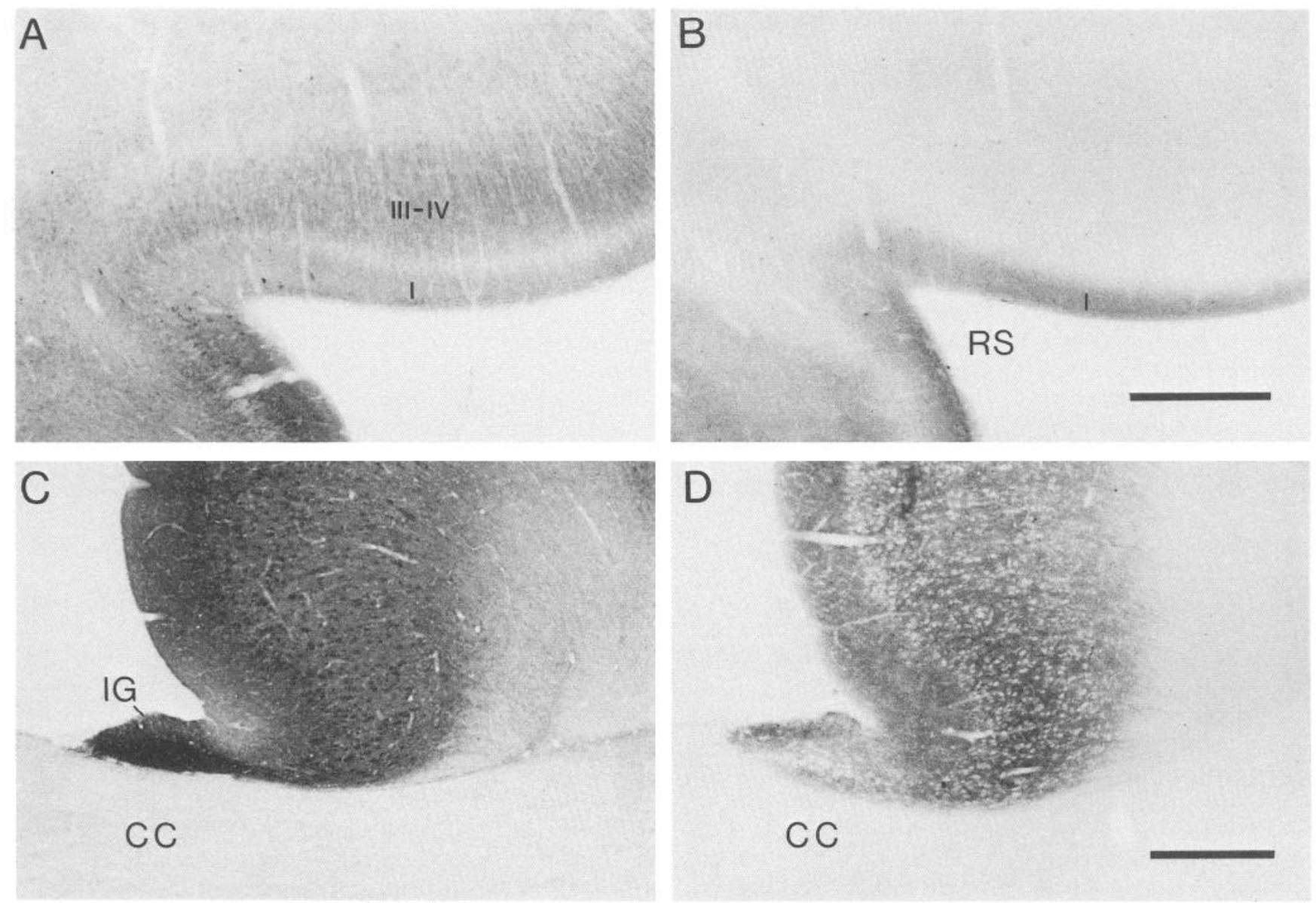

Figure 7. $A$ and $B$, Comparison of the immunostaining in serial $70 \mu \mathrm{m}$ sections through perirhinal cortex of a P1 kitten stained for CaM kinase II-like immunoreactivity $(A)$ and SV48-like immunoreactivity $(B)$. In both immunostains, a change in pattern appears at the rhinal sulcus $(R S)$, the region of the transition from neocortex to paleocortex. In neocortex, layers I and III-IV had the most intense CaM kinase II-like immunoreactivity, but at the rhinal sulcus, the cortical staining pattern abruptly changed to one of dense immunoreactivity in laminae I and II and moderate immunostaining of lamina III of the piriform cortex. Many neurons in the piriform cortex had densely stained processes and perikarya. These were most often found in the superficial layers of the cortex. $C$ and $D$, Comparison of staining patterns of CaM kinase II-like (C) and SV48-like $(D)$ immunoreactivities in serial $70 \mu \mathrm{m}$ sections of the adult cingulate cortex. Note the densely stained cell bodies in a dark neuropil and the contrasting pale white matter in $C$. By contrast, unstained cell bodies appear as "ghosts" backed by a darkly staining neuropil in $D$. $C C$, Corpus callosum; $I G$, indusium griseum. Scale bar, $0.5 \mathrm{~mm}$.

(Moon Edley, 1983; Moon, 1984; van der Kooy, 1984). These studies demonstrated that although the ligand-binding patterns were not identical with those of the normal animal, disruption or blockade of a source of afferent influence did not prevent formation of a patchy pattern of striatal architecture.

The influence of the formation of efferent connections in the induction of maturational events in the striatum is not well understood. Fishell and van der Kooy $(1985,1987)$ found that, in the rat, striatonigral neurons with early projections reaching the midbrain by E18 are homogeneously distributed at E19, but such neurons are clustered by E21. Apparently, axons of islandic neurons begin to reach target regions (E17-18) prior to the arrival of the cell bodies at their final destination within a cluster (E19). Striatonigral projections from matrix neurons, present in the adult, were not found until several days later (P2-P6). Fishell and van der Kooy suggest (see also Marchand and Lajoie, 1984) that, via migration, later-generated matrix cells intercalate themselves among islandic cells and that the retrogradely labeled island cells in the caudoputamen are thereby passively aggregated into clusters. Interestingly, projections between striatal cells and nigral cells appear to correlate with gradients in neurogenesis (see Bayer, 1984). Consequently, early-generated is-

\footnotetext{
Figure 6. Distribution of CaM kinase II-like immunoreactivity $(A)$, AChE staining $(B)$, SV48-like immunoreactivity $(C)$, and TH-like immunoreactivity $(D)$ in a serial set of coronal $70 \mu \mathrm{m}$ sections through the midstriatum of the adult cat. $A$, CaM kinase II-like immunoreactivity appears to be relatively homogeneously distributed in the caudate nucleus $(C N)$ and putamen $(P)$, while inhomogeneities remain ventral. $B$, AChE staining reveals the classic AChE-poor striosomes (examples marked by asterisks) in a densely stained matrix. $C$, No obviously delineated pale zones were present in SV48-immunostained sections, but there did appear to be a mottled pattern in which some paler zones could be aligned with striosomes in adjacent sections (asterisks). D, TH-like immunostaining was characteristically dense in the matrix and pale zones in register with the AChEpoor striosomes could be clearly identified (asterisks). The tips of the lines marked by asterisks are exactly aligned in adjacent sections. AC, Anterior commissure; $I C$, internal capsule. Scale bar, $1 \mathrm{~mm}$.
} 
landic neurons contact early-generated cells of the substantia nigra. Thus, the reciprocal limbs of the nigrostriatonigral pathways involving striosomes, thought to represent functionally important trans-striatal loops (Aghajanian, 1978; Gerfen, 1985; Graybiel, 1986; Jimenez-Castellanos and Graybiel, 1987), appear to be among the earliest striatal connections to be established.

Several laboratories have now reported that an initial homogeneous appearance of TH-like immunoreactivity in the striatum precedes the onset of clustering of TH-immunoreactive elements into dopamine islands (Specht et al., 1981c; Moon Edley and Ilerkenham, 1984). What the nature of this clustering is has not yet been established, but several observations reported here may serve as clues. First, as TH-like immunoreactive fibers invade more and more medial parts of the striatum during development, there is always weak immunoreactivity in the nonislandic matrix surrounding the islands. Medial islands and matrix are always more weakly immunoreactive than lateral islands and matrix. This suggests that, despite the prominence of islandic clusters of TH-immunoreactive elements, the dopamine-containing innervation of island sites and matrix sites develops synchronously, though to differing extents at each developmental age. Accordingly, though there are clearly more TH-positive elements in the islands than in the matrix in any given locale, developmental hypotheses must take into account a differential but linked maturation of the islandic and nonislandic compartments of the dopaminergic innervation of the striatum.

Second, it was evident that, even though the 3 markers we followed were first expressed in the striatum at different times, their initial expression was in the same location: CaM kinase II-like immunoreactivity first appeared in the lateral striatum, as did the earliest detected TH-positive fibers and, after a time lag, the first clear islandic concentrations of SV48-like immunoreactivity. This regional coincidence of first expression of the 3 markers - collectively marking cell bodies, synaptic neuropil, and dopamine-containing afferents - is remarkable in that it suggests a repetition of spatial gradients of maturation for each marker. This in turn implies that all 3 come under the influence of a shared topographic control despite the fact that each expresses overt compartmentalization at a different time. The identity of the factors responsible for this topographic control is an open and interesting question.

Third, as discussed further in the next section, the initial concentration of TH-positive elements into islands appears to precede equally overt concentration of synapses detectable by their SV48-like immunoreactivity; but over a long developmental period, the islands are foci with much higher concentrations of SV48-positive synapses than the surrounding matrix. This suggests that, if not initially, at least for much of development the formation of islands of $\mathrm{TH}$-like immunoreactivity (and of catecholamine histofluorescence) may represent a heightened formation of dopamine-containing terminals in the islands relative to the matrix. Finally, at the time when earlyarriving $\mathrm{TH}$-positive afferents had reached the putamen and the lateral edge of the caudate nucleus but were still not perceptibly clustered, we found in serially adjoining sections that there were faint niduses of AChE positivity distributed at intervals in the putamen and along the lateral rim of the caudate nucleus. The niduses had the spacing characteristic of the future first-appearing dopamine islands. Later in development it is known that AChE-positive patches are strictly coextensive with do- pamine islands (Butcher and Hodge, 1976; Graybiel et al., 1981). The early AChE-positive niduses could thus represent the beginning of the formation of dopamine islands. The location of $\mathrm{AChE}$ in relation to the dopamine-containing afferents at this stage is an important issue to resolve, for the expression of $\mathrm{AChE}$ could, according to our finding of the AChE-positive niduses, be a leading, even inductive, event in island formation. Interestingly, it has been shown that AChE is distributed in clusters along the axons of cultured sympathetic neurons (Rotundo and Carbonetto, 1987).

The role of extracellular matrix in the formation of dopamine islands appcars to bc largely uncxplored. Steindler et al. (1988) report the appearance of glycoconjugate boundaries which border AChE-rich, TH-rich zones in the early postnatal mouse. Along with the changing pattern of $\mathrm{TH}$ and AChE staining during the second postnatal week, these boundaries disappear. Prenatal studies of the first appearance and temporal relationships of this transient compartmental marker could provide important clues towards determining the mechanism of island formation and maturation.

\section{Synaptic maturation in the striatum}

A major finding of the present study is that patches of CaM kinase II-positive neurons and neuropil appeared before synapse-rich clusters could be detected with the SV48 antibody and before more than at most very weak SV48-like immunoreactivity was present. Furthermore, there was widespread invasion of the striatum by TH-immunoreactive fibers before SV48-like immunoreactivity is appreciable. It is possible that early synapses formed in low numbers escaped light microscopic detection with the SV48 immunhistochemistry. However, the considerable intensity of staining of the CaM kinase II immunoreactive patches compared with the apparently delayed and faint appearance of SV48-positive immunoreactivity in the island system argues against a primary role for synaptogenesis in the induction of an islandic arrangement of cells. This evidence is compatible with the notion that islandic cells may already be sufficiently differentiated to respond selectively to the inductive influence of striatal afferents.

The correspondence of the SV48-positive clusters with THrich islands strongly suggests that synaptogenesis in the striatum is initially concentrated in the dopamine islands. It has been suggested that the formation of synapses can influence dendritic development (Rakic, 1975). This could be true even for transient synapses, which comprise, according to the evidence of Specht and her colleagues $(1981 a-c)$, much of the early synaptic population of the caudoputamen. These authors report that early $\mathrm{TH}$-positive synapses in the E 14.5 rat striatum primarily contact neuronal cell bodies, whereas in the adult, contacts are usually found on dendritic spines (Specht et al., 1981a, b; Freund et al., 1984). Early synapses on perikarya are in a prime location to influence subsequent dendritic elaboration. In the primate neostriatum, Brand and Rakic (1984) reported that the formation of immature dendrites begins just prior to synaptogenesis but that subsequent elaboration of dendritic arbors is correlated with the arrival of axons from the neocortex and probably the substantia nigra (see also DiFiglia et al., 1980; Hull et al., 1981). Other studies also suggest a certain lability of early synapses in the striatum. Goldman-Rakic (1981) observed that the early corticostriatal afferents in the primate are at first homogeneously distributed but are subsequently eliminated from islandic regions. Snyder-Keller and colleagues (1986) have found evidence 
for transient but patchy intrastriatal connections in the newborn rat. The present findings combined with these earlier studies lead to the prediction that the neurons of the islands (futurc striosomes) might lead in dendritic maturation and that differences in timing of synaptic influence could be important not only in the elaboration of the dopamine island system and compartmentalization of other neurotransmitter systems in the developing striatum, but also in determining the ultimate compartmentalization of some dendritic arbors within the striosome and matrix subdivisions of the mature striatum (Gerfen, 1984; Chesselet and Graybiel, 1986; Bolam et al., 1988).

\section{Functional implications of differential CaM kinase II distribution}

In addition to suggesting that establishment of neuronal compartments in the striatum precedes macroscopic clustering of dopamine-containing nigrostriatal fibers and terminals, the findings presented here implicate the dopamine islands as sites of carly functional transmission within the striatum. In the islands, fibers containing the enzyme for catecholamine synthesis are present; there is evidence for differentially high concentrations of vesicle-containing terminals in the islands; and the presumed target cells of the islandic dopamine fibers produce CaM kinase II, an enzyme probably closely related to signal transduction. Germane to this conclusion are 3 developmentally significant features of CaM kinase II. (1) It is concentrated in postsynaptic densities and may be involved in receptor regulation via phosphorylation (Kennedy, 1983; Lisman, 1985). (2) Via autophosphorylation, CaM kinase II can function as a molecular switch (Miller and Kennedy, 1986; see also review by Schwartz and Greenberg, 1987). It has been suggested that this switch mechanism provides a means by which long-term changes in neuronal function can be made in response to transient calcium influxes (Miller and Kennedy, 1986; Schwartz and Greenberg, 1987). (3) CaM kinase II has an extremely high affinity for synapsin 1 (Bennett et al., 1983), which in its dephosphorylated form binds to synaptic vesicles and decreases synaptic transmission. Phosphorylation of synapsin 1 decreases its affinity for synaptic vesicles and subsequently increases the amount of transmitter released (Llinás et al., 1985). Clearly, these characteristics of CaM kinase II could be important in the development and stabilization of neuronal circuits. In the striatum, the early concentration of this kinase in the sites of future striosomes (dopamine islands) could serve in selective enhancement of synaptic efficacy in the dopamine island system and help in shaping the intrastriatal and trans-striatal circuitry that characterizes the striosomal labyrinths at maturity.

\section{References}

Aghajanian, G. K. (1978) Feedback regulation of central monoaminergic neurons: Evidence from single cell recording studies. Essays Neurochem. Neuropharmacol. 3: 1-32.

Bayer, S. A. (1984) Neurogenesis in rat striatum. Int. J. Dev. Neurosci. 2: $163-175$.

Bennett, M. K., N. E. Erondu, and M. B. Kennedy (1983) Purification and characterization of a calmodulin-dependent protein kinase that is highly concentrated in brain. J. Biol. Chem. 258: 12735-12744.

Bolam, J. P., P. N. Izzo, and A. M. Graybiel (1988) Cellular substrate of the histochemically defined striosome/matrix system of the caudate nucleus: A combined Golgi and immunocytochemical study in cat and ferret. Neuroscience 24: 853-875.

Brand, S., and P. Rakic (1984) Cytodifferentiation and synaptogenesis in the neostriatum of fetal and neonatal rhesus monkeys. Anat. Embryol. 169: 21-34.
Butcher, L. L., and G. K. Hodge (1976) Postnatal development of acetylcholinesterase in the caudate-putamen nucleus and substantia nigra of rats. Brain Res. 106: 223-240.

Chesselet, M. F., and A. M. Graybiel (1986) Striatal neurons expressing somatostatin-like immunoreactivity: Evidence for a peptidergic interneuronal system in the cat. Neuroscience 17: 547-571.

DiFiglia, M., P. Pasik, and T. Pasik (1980) Early postnatal development of the monkey neostriatum: A Golgi and ultrastructural study. J. Comp. Neurol. 190: 303-331.

Erondu, N. E., and M. B. Kennedy (1985) Regional distribution of type II $\mathrm{Ca}^{2+} /$ calmodulin-dependent protein kinase in rat brain. $\mathbf{J}$. Neurosci. 5: 3270-3277.

Ferrante, R. J., M. F. Beal, N. W. Kowall, E. P. Richardson, Jr., and J. B. Martin (1987) Sparing of acetylcholinesterase-containing striatal neurons in Huntington's disease. Brain Res. 411: 162-166.

Fishell, G., and D. van der Kooy (1985) Development of the striatonigral pathway reveals a possible mechanism of striatal compartmentalization. Soc. Neurosci. Abstr. 11: 1163.

Fishell, G., and D. van der Kooy (1987) Pattern formation in the striatum: Developmental changes in the distribution of striatonigral neurons. J. Neurosci. 7: 1969-1978.

Foster, G. A., M. Schultzberg, T. Hökfelt, M. Goldstein, H. C. Hemmings, Jr., C. C. Ouimet, S. I. Walaas, and P. Greengard (1987) Development of a dopamine- and cyclic adenosine $3^{\prime}: 5^{\prime}$-monophosphate regulated phosphoprotein (DARPP-32) in the prenatal rat central nervous system, and its relationship to the arrival of presumptive dopaminergic innervation. J. Neurosci. 7: 1994-2018.

Freund, T. F., J. F. Powell, and A. D. Smith (1984) Tyrosine hydroxylase-immunoreactive boutons in synaptic contact with identified striatonigral neurons, with particular reference to dendritic spines. Neuroscience 13: 1189-1215.

Geneser-Jensen, F. A., and J. W. Blackstad (1971) Distribution of acetylcholinesterase in the hippocampal region of the guinea pig. I. Fntorhinal area, parasubiculum, and presubiculum. Z. Zellforsch. Mikrosk. Anat. 114: 460-481.

Gerfen, C. R. (1984) The neostriatal mosaic: Compartmentalization of corticostriatal input and striatonigral output systems. Nature 311 : 461-464.

Gerfen, C. R. (1985) The neostriatal mosaic. I. Compartmental organization of projections from the striatum to the substantia nigra in the rat. J. Comp. Neurol. 236: 454-476.

Gerfen, C. R. (1986) The development and biochemical basis of dual "patch" and "matrix" nigrostriatal dopaminergic systems in the rat. Soc. Neurosci. Abstr. 12: 1327.

Goedert, M., S. P. Hunt, P. W. Mantyh, and P. C. Emson (1985) The ontogenetic development of neurotensin-like immunoreactivity and neurotensin receptors in the cat striatum. Dev. Brain Res. 20:127131.

Golden, G. S. (1972) Embryologic demonstration of a nigrostriatal projection in the mouse. Brain Res. 44: 278-282.

Goldenring, J. R., B. Gonzales, J. S. McGuire, Jr., and R. J. DeLorenzo (1983) Purification and characterization of a calmodulin-dependent kinase from rat brain cytosol able to phosphorylate tubulin and microtubule-associated proteins. J. Biol. Chem. 258: 12632-12640.

Goldenring, J. R., J. S. McGuire, Jr., and R. J. DeLorenzo (1984) Identification of the major postsynaptic density protein as homologous with the major calmodulin-binding subunit of a calmodulindependent protein kinase. J. Neurochem. 42: 1077-1084.

Goldman-Rakic, P. S. (1981) Prenatal formation of cortical input and development of cytoarchitectonic compartments in the neostriatum of the rhesus monkey. J. Neurosci. 1: 721-735.

Grab, D. J., R. K. Carlin, and P. Siekevitz (1981) Function of calmodulin in postsynaptic densities. II. Presence of a calmodulin-activatable protein kinase activity. J. Cell Biol. 89: 440-448.

Graybiel, A. M. (1984a) Modular patterning in the development of the striatum. In Cortical Integration, F. Reinoso-Suarez and C. AjmoneMarsan, eds., pp. 223-235, Raven, New York.

Graybiel, A. M. (1984b) Correspondence between the dopamine islands and striosomes of the mammalian striatum. Neuroscience 13: 1157-1187.

Graybiel, A. M. (1986) Dopamine-containing innervation of the striatum: Subsystems and their striatal correspondents. In Recent Developments in Parkinson's Disease, S. Fahn et al., eds., pp. 1-16, Raven, New York.

Graybiel, A. M., and M. F. Chesselet (1984) Striatal cell bodies ex- 
pressing dynorphin B-like (DYN) and metenkephalin-like (ENK) immunoreactivities have complementary distributions in kittens and contrasting distributions in cats. Soc. Neurosci. Abstr. 10: 514.

Graybiel, A. M., and T. L. Hickey (1982) Chemospecificity of ontogenetic units in the striatum: Demonstration by combining ${ }^{3} \mathrm{H}$ thymidine neuronography and histochemical staining. Proc. Natl. Acad. Sci. USA 79: 198-202.

Graybiel, A. M., and H. Newman-Gage (1985) The developmental relationship between dopamine islands and early striosomal neuron clusters in the fetal cat striatum. Soc. Neurosci. Abstr. 11: 205.

Graybiel, A. M., and C. W. Ragsdale (1978) Histochemically distinct compartments in the striatum of human, monkey, and cat demonstrated by acetylthiocholinesterase staining. Proc. Natl. Acad. Sci. USA 75: 5723-5726.

Graybiel, A. M., and C. W. Ragsdale (1983) Biochemical anatomy of the striatum. In Chemical Neuroanatomy, P. C. Emson, ed., pp. 427504, Raven, New York

Graybiel, A. M., V. M. Pickel, T. H. Joh, D. J. Reis, and C. W. Ragsdale, Jr. (1981) Direct demonstration of a correspondence between the dopamine islands and acetylcholinesterase patches in the developing striatum. Proc. Natl. Acad. Sci. USA 78: 5871-5875.

Graybiel, A. M., E. C. Hirsch, and Y. A. Agid (1987) Differences in tyrosine hydroxylase-like immunoreactivity characterize the extrastriosomal matrix at maturity. Proc. Natl. Acad. Sci. USA 84: $303-$ 307.

Hemmings, H. C., Jr., P. Greengard, H. Y. L. Tung, and P. Cohen (1984) DARPP-32, a dopamine-regulated neuronal phosphoprotein, is a potent inhibitor of protein phosphatase. Nature 310:502-505.

Hull, C. D., J. P. McAllister, M. S. Levine, A. M. Adinolfi (1981) Quantitative developmental studies of feline neostriatal spiny neurons. Dev. Brain Res. 1: 309-332.

Jimenez-Castellanos, J., and A. M. Graybiel (1987) Subdivisions of the dopamine-containing A8-A9-A10 complex identified by their differential mesostriatal innervation of striosomes and extrastriosomal matrix. Neuroscience 23: 223-242.

Kennedy, M. B. (1983) Experimental approaches to understanding the role of protein phosphorylation in the regulation of neuronal function. Annu. Rev. Neurosci. 6: 493-525.

Kennedy, M. B., M. K. Bennett, and N. E. Erondu (1983a) Biochemical and immunochemical evidence that the "major postsynaptic density protein" is a subunit of a calmodulin-dependent protein kinase. Proc. Natl. Acad. Sci. USA 80: 7357-7361.

Kennedy, M. B., T. McGuinness, and P. Greengard (1983b) A calcium/calmodulin-dependent protein kinase from mammalian brain that phosphorylates synapsin I: Partial purification and characterization. J. Neurosci. 3: 818-831.

Kent, J. L., C. B. Pert, and M. Herkenham (1982) Ontogeny of opiate receptors in rat forebrain: Visualization by in vitro autoradiography. Dev. Brain Res. 2: 487-504.

Lanca, A. J., S. Boyd, B. E. Kolb, and D. van der Kooy (1986) The development of a patchy organization in the ral striatum. Dev. Brain Res. 27: 1-10.

LeVine III, H., N. E. Sahyoun, and P. Cuatrecasas (1985) Calmodulin binding to the cytoskeletal neuronal calmodulin-dependent protein kinase is regulated by autophosphorylation. Proc. Natl. Acad. Sci. USA 82: 287-291.

Lisman, J. E. (1985) A mechanism for memory storage insensitive to molecular turnover: A bistable autophosphorylating kinase. Proc. Natl. Acad. Sci. USA 82: 3055-3057.

Llinás, R., T. L. McGuinness, C. S. Leonard, M. Sugimori, and P. Greengard (1985) Intraterminal injection of synapsin I or calcium/ calmodulin-dependent protein kinase II alters neurotransmitter release at the squid giant synapse. Proc. Natl. Acad. Sci. USA 82: 30353039.

Lowenstein, P. R., P. A. Slesinger, H. S. Singer, L. C. Walker, M. F. Casanova, D. L. Price, and J. T. Coyle (1986) Development of cholinergic and dopaminergic pre- and postsynaptic markers in the baboon and human striatum. Soc. Neurosci. Abstr. 16: 1230.

Marchand, R., and L. Lajoie (1986) Histogenesis of the striopallidal system in the rat. Neurogenesis of its neurons. Neuroscience 17:573590.

Matthew, W. D., L. Tsavaler, and L. F. Reichardt (1981) Identification of a synaptic vesicle-specific membrane protein with a wide distribution in neuronal and neurosecretory tissue. J. Cell Biol. 91: 257269.
Miller, S. G., and M. B. Kennedy (1986) Regulation of brain type II $\mathrm{Ca}^{2+} /$ calmodulin-dependent protein kinase by autophosphorylation: $\mathrm{A} \mathrm{Ca}^{2+}$-triggered molecular switch. Cell 44: 861-870.

Moon, S. L. (1984) Prenatal haloperidol alters striatal dopamine and opiate receptors. Brain Res. 323: 109-113.

Moon Edley, S. (1983) Effects of prenatal haloperidol on receptors in the developing rat striatum: Opposite effects in naloxone and spiperone binding. Soc. Neurosci. Abstr. 9: 874.

Moon Edley, S., and M. Herkenham (1984) Comparative development of striatal opiate receptors and dopamine revealed by autoradiography and histofluorescence. Brain Res. 305: 27-42.

Murrin, C. L., and J. R. Ferrer (1984) Ontogeny of the rat striatum: Correspondence of dopamine terminals, opiate receptors and acetylcholinesterase. Neurosci. Lett. 47: 155-160.

Nastuk, M. A., and A. M. Graybiel (1985a) Patterns of muscarinic cholinergic binding in the striatum and their relation to dopamine islands and striosomes. I. Comp. Neurol. 237: 176-194.

Nastuk, M. A., and A. M. Graybiel (1985b) Differential distribution of $\mathrm{M} 1$ and $\mathrm{M} 2$ muscarinic binding sites in the striatum of the adult and immature cat. Soc. Neurosci. Abstr. 11: 204.

Nestler, E. J., S. I. Walaas, and P. Greengard (1984) Neuronal phosphoproteins: Physiological and clinical implications. Science 225 $1357-1364$.

Newman-Gage, H., and A. M. Graybiel (1985) Developmental anatomy of dopamine islands in the caudate nucleus of the cat. Soc. Neurosci. Abstr. 11: 206.

Newman-Gage, H., and A. M. Graybiel (1986) Synapse-related antibody immunostaining in the developing cat striatum: A light and electron microscopic study. Soc. Neurosci. Abstr. 12: 1326.

Newman-Gage, H., A. M. Graybiel, and W. D. Matthew (1986) Immunoreactivity of synaptic vesicle protein in the striatum: Ontogenetic progression from islandic to diffuse distribution. In International Basal Ganglia Society Symposium, Vol. 2, M. Carpenter and J. Jayaramon, eds., p. 30, Plenum, N.Y.

Olson, L., A. Seiger, and K. Fuxe (1972) Heterogeneity of striatal and limbic dopamine innervation: Highly fluorescent islands in developing and adult rats. Brain Res. 44: 283-288.

Ouimet, C. C., T. L. McGuinness, and P. Greengard (1984) Immunocytochemical localization of calcium/calmodulin-dependent protein kinase II in rat brain. Proc. Natl. Acad. Sci. USA 81: 5604-5608.

Ragsdale, C. W., and A. M. Graybiel (1979) Acetylcholinesterase staining in the striatum of the fetal and neonatal cat. Neurosci. Lett. Suppl. 3: $\mathrm{S} 26$

Rakic, P. (1975) Role of cell interaction in development of dendritic patterns. In Advances in Neurology, G. W. Kreutzberg, ed., pp. 117134, Raven, New York.

Rotundo, R. L., and S. T. Carbonetto (1987) Neurons segregate clusters of membrane-bound acetylcholinesterase along their neurites. Proc. Natl. Acad. Sci. USA 84: 2063-2067.

Schulman, H. (1984) Phosphorylation of microtubule-associated proteins by a $\mathrm{Ca}^{2+} /$ calmodulin-dependent protein kinase. J. Cell Biol. 99 . 11-19.

Schwartz, J. H., and S. M. Greenberg (1987) Molecular mechanisms for memory: Second-messenger induced modifications of protein kinases in nerve cells. In Annual Review of Neuroscience, W. M. Cowan et al., eds., pp. 459-476, Annual Reviews, Inc., Palo Alto, CA.

Snyder-Keller, A. M., M. J. Zigmond, and R. D. Lund (1986) Fluorogold labels patches of striatal neurons after striatal injection into twoday old rats. Soc. Neurosci. Abstr. 12: 1543.

Specht, L. A., V. M. Pickel, T. H. Joh, and D. J. Reis (1978) Immunocytochemical localization of tyrosine hydroxylase in processes within the ventricular zone of prenatal rat brain. Brain Res. 156:315321.

Specht, L. A., V. M. Pickel, T. H. Joh, and D. J. Reis (1981a) Fine structure of the nigrostriatal anlage in fetal rat brain by immunocytochemical localization of tyrosine hydroxylase. Brain Res. 218: 4965.

Specht, L. A., V. M. Pickel, I. H. Joh, and D. J. Reis (1981b) Light microscopic immunocytochemical localization of tyrosine hydroxylase in prenatal rat brain. I. Early ontogeny. J. Comp. Neurol. 199: 233-254

Specht, L. A., V. M. Pickel, T. H. Joh, and D. J. Reis (1981c) Lightmicroscopic immunocytochemical localization of tyrosine hydroxylase in prenatal rat brain. II. Late ontogeny. J. Comp. Neurol. 199: 255-276. 
Steindler, D. A., T. F. O'Brien, and N. G. F. Cooper (1988) Glycoconjugate boundaries during early postnatal development of the neostriatal mosaic. J. Comp. Neurol. 267: 357-389.

Tennyson, V. M., R. E. Barrett, G. Cohen, L. Côté, R. Heikkila, and C. Mytilineou (1972) The developing neostriatum of the rabbit: Correlation of fluorescence histochemistry, electron microscopy, endogenous dopamine levels and $\left[{ }^{3} \mathrm{H}\right]$ dopamine uptake. Brain Res. 46 : 251-285.

van der Kooy, D. (1984) Developmental relationships between opiate receptors and dopamine in the formation of caudate-putamen patches. Dev. Brain Res. 14: 300-303.

van der Kooy, D., and G. Fishell (1987) Neuronal birthdate underlies the development of striatal compartments. Brain Res. 401: 155-161.

Vulliet, P. R., J. R. Woodget, and P. Cohen (1984) Phosphorylation of tyrosine hydroxylase by calmodulin-dependent multiprotein $\mathrm{ki}$ nase. J. Biol. Chem. 259: 13680-13683.
Walaas, S. I., D. W. Aswad, and P. Greengard (1983) A dopamineand cyclic AMP-regulated phosphoprotein enriched in dopamineinnervated brain regions. Nature 301: 69-71.

Yamauchi, T., and H. Fujisawa (1981) Tyrosine 3-monooxygenase is phosphorylated by $\mathrm{Ca}^{2+}$-calmodulin-dependent protein kinase, followed by activation by activator protein. Biochem. Biophys. Res. Commun. 100: 807-813.

Yamauchi, T., and H. Fujisawa (1982) Phosphorylation of microtubule-associated protein 2 by calmodulin-dependent protein kinase (kinase II) which occurs only in the brain tissues. Biochem. Biophys. Res. Commun. 109: 975-981.

Yamauchi, T., and H. Fujisawa (1983) Purification and characterization of the brain calmodulin-dependent protein kinase (kinase II) which is involved in the activation of tryptophan 5-monooxygenase. Eur. J. Biochem. 132: 15-21. 